\title{
The effect of selenium on thyroid status in a population with marginal selenium and iodine status
}

\author{
Christine D. Thomson*, Sarah K. McLachlan, Andrea M. Grant, Elaine Paterson and Anna J. Lillico \\ Department of Human Nutrition, University of Otago, Dunedin, New Zealand \\ (Received 24 February 2005 - Revised 5 July 2005 - Accepted 9 July 2005)
}

\begin{abstract}
The effects of Se on thyroid metabolism in a New Zealand population are investigated, including (a) the relationship between Se and thyroid status, and (b) the effect of Se supplementation on thyroid status. The data used come from two cross-sectional studies of Se, I, thyroid hormones and thyroid volume (studies 1 and 4), and three Se intervention studies in which thyroid hormones, Se and glutathione peroxidase (GPx) activities were measured (studies 2, 3 and 5). There were no significant correlations between Se status and measures of thyroid status after controlling for sex at baseline or after supplementation in any of the studies. When data from study 4 were divided into two groups according to plasma Se, plasma thyroxine ( $\left.\mathrm{T}_{4}\right)$ was lower in males with higher plasma Se levels $(P=0 \cdot 009)$. Se supplementation increased plasma Se and GPx activity, but produced only small changes in plasma $\mathrm{T}_{4}$ and triiodothyronine $\left(\mathrm{T}_{3}\right): \mathrm{T}_{4}$ ratio. In study 2 , there was a significant reduction in plasma $\mathrm{T}_{4}(P=0.0045)$. In studies 3 and 5 there were small decreases in plasma $\mathrm{T}_{4}$ and a small increase in the $\mathrm{T}_{3}: \mathrm{T}_{4}$ ratio, which were not significantly different from placebo groups. Lack of significant associations between plasma Se and thyroid status, and only small changes in $\mathrm{T}_{4}$ suggest that Se status in New Zealand is close to adequate for the optimal function of deiodinases. Adequate plasma Se may be approximately $0.82-0.90 \mu \mathrm{mol} / 1$, compared with $1.00-1.14 \mu \mathrm{mol} / 1$ for maximal GPx activities.
\end{abstract}

Selenium: Iodine: Thyroid status: New Zealand

The role of Se as an integral part of the iodothyronine deiodinase enzymes links Se and I in a potentially important interrelationship, in which the degree of adequacy of one trace element may influence the metabolism of another. The iodothyronine deiodinase enzymes convert the pro-hormone thyroxine $\left(\mathrm{T}_{4}\right)$ to the active form triiodothyronine $\left(\mathrm{T}_{3}\right)$ required for normal growth and development, and for energy production and $\mathrm{O}_{2}$ consumption in cells. Type 1 deiodinase, abundant in liver and kidney, is sensitive to Se deficiency, which decreases deiodinase activity and therefore $T_{4}$ to $T_{3}$ conversion, resulting in a decrease in the $\mathrm{T}_{3}: \mathrm{T}_{4}$ ratio. On the other hand, type 2 and type 3 deiodinases are less sensitive to Se deficiency, indicating their importance for the maintenance of normal thyroid hormone levels (Arthur et al. 1999). In addition, Se as the antioxidant enzyme glutathione peroxidase $(\mathrm{GPx})$ may protect the thyroid gland from oxidative damage due to any excess $\mathrm{H}_{2} \mathrm{O}_{2}$ produced during thyroid hormone synthesis (Arthur et al. 1999). Thus, Se deficiency may exacerbate some effects of I deficiency and may have a role in the aetiology of I-deficiency disorders (Arthur et al. 1999; Arthur \& Beckett, 1999).

The interaction between $\mathrm{I}$ and $\mathrm{Se}$ is of particular interest in New Zealand, whose inhabitants have relatively low intakes of both trace elements. The Se status is lower than that of residents of many other countries (Robinson, 1989; Diplock, 1993; Combs, 2001; Thomson, 2004b), even though blood Se of New Zealanders has increased in recent years due to changes in dietary patterns and increases in $\mathrm{Se}$ concentrations of some foods
(Thomson \& Robinson, 1996; Thomson, 2004b). Evidence that Se supplementation results in an increase in the selenoproteins, GPx and selenoprotein P (Thomson et al. 1993; Duffield et al. 1999) suggests that Se intake is insufficient for maximal activity of these proteins.

Despite iodisation of salt since the 1930s, a decrease in I status of New Zealanders during the past two decades has been shown and, according to WHO, UNICEF and International Council for the Control of Iodine Deficiency Disorders criteria, urinary I excretion is indicative of mild I deficiency (World Health Organization et al. 1994; Thomson et al. 1997a,b, 2001a,b; Skeaff et al. 2002, 2005). This is likely to be due to the reduction in use of iodophor cleaning agents in the dairy industry resulting in lower I concentrations in dairy products, as well as to changes in dietary patterns resulting in a reduction of iodised salt intake. Observations of enlarged thyroid glands and elevated plasma thyroglobulin (Tg) levels among adults in the Otago region of the South Island of New Zealand (Thomson et al. 2001b), and children (Skeaff et al. 2002) confirm a return to mild I deficiency. The adequacy of Se status thus becomes a focus of attention.

Although our blood Se concentrations may not be in the range in which effects on thyroid function have been observed, the combination of low Se status and mild I deficiency may be significant. A number of human studies have shown alterations in the $T_{3}: T_{4}$ ratio associated with low Se and I status (Kvícala et al. 1995; Olivieri et al. 1996; Ravaglia et al. 2000). Therefore, it is important to determine whether there are any detrimental effects of marginal 
status of Se and I in our population. The present paper examines the results of five studies in which the interaction between Se and I has been investigated, including (a) the relationship between Se status and thyroid status in a New Zealand population and (b) the effect of Se supplementation on measures of thyroid status: thyroid-stimulating hormone (TSH), $\mathrm{Tg}$ and the $\mathrm{T}_{3}: \mathrm{T}_{4}$ ratio.

\section{Methods}

Blood samples were available for thyroid hormone analysis from three previous Se intervention studies (studies 2, 3 and 5; Duffield et al. 1999; Paterson, 2000; CD Thomson, AM Grant and SK McLachlan, unpublished results), and for analysis of Se, from two previous cross-sectional studies of I and thyroid status (studies 1 and 4; Thomson et al. 1997a,b). These studies, carried out in the South Island of New Zealand, have provided data on interrelationships among Se, I and thyroid status of New Zealand residents.

\section{Study 1: Dunedin and Waikato blood donors (1993-4)}

One hundred and eighty-nine subjects (102 males and eighty-seven females) aged 18-68 years were recruited from the Dunedin Blood Transfusion Centre, in the South Island of New Zealand, and 144 (sixty-seven males and seventy-seven females) from the Waikato Blood Transfusion Centre, in the North Island of New Zealand, between November 1993 and June 1994. Blood was taken for assays of serum free $\mathrm{T}_{3}$, free $\mathrm{T}_{4}$ and TSH. Se concentrations and GPx activities were measured in 2004 in plasma and whole-blood samples stored at $-80^{\circ} \mathrm{C}$. Subjects collected a complete $24 \mathrm{~h}$ urine specimen for analysis of I and Se. Sample preparation and analyses (except for Se and GPx) are described elsewhere (Thomson et al. 1997a).

\section{Study 2: Dunedin subjects with low selenium status (1995)}

Fifty-two adults (seventeen males and thirty-five females) aged 19-59 years, with whole-blood Se concentrations less than $1.26 \mu \mathrm{mol} / \mathrm{l}(100 \mu \mathrm{g} / \mathrm{l})$, were recruited from a group of healthy volunteers in 1995 in Dunedin, New Zealand (Duffield et al. 1999). Subjects were recruited into a randomised double-blind intervention trial designed to determine the lowest level of supplementation necessary for maximisation of plasma GPx activity. Five groups of ten or eleven subjects consumed daily tablets containing either a placebo $(<1 \mu \mathrm{g} \mathrm{Se})$ or varying levels of Se $(10$, 20, 30 or $40 \mu \mathrm{g}$ as L-selenomethionine; Westar Nutrition Inc., Costa Mesa, CA, USA) for 20 weeks. Subjects were asked not to consume high-Se foods during the study period. Blood samples were obtained every 2 weeks for 2 months, then every 4 weeks for a further 12 weeks for analysis of Se and GPx activity. Serum total $\mathrm{T}_{4}$ and $\mathrm{Tg}$ were determined in the baseline and 20-week samples stored at $-80^{\circ} \mathrm{C}$. Urine samples $(24 \mathrm{~h})$ were analysed for Se and I. Dietary intakes were determined by analysing Se and I in duplicate composites of all food consumed daily by each subject for $3 \mathrm{~d}$. The experimental design and analytical methods are described elsewhere (Duffield \& Thomson, 1999; Duffield et al. 1999).

\section{Study 3: Dunedin smokers (1995-6)}

Eighty-one smokers aged 19-52 years were screened for wholeblood Se concentrations and GPx activities in 1995 and 1996 and those individuals (thirty-six males and thirty-six females) with whole-blood Se concentration less than $1.0 \mu \mathrm{mol} / \mathrm{l}$, or wholeblood Se concentration between $1.0-1.2 \mu \mathrm{mol} / \mathrm{l}$ and wholeblood GPx activities less than 20 units/g Hb, were invited to participate in the present study. During the intervention period, twelve subjects (six males and six females) withdrew from the study for a variety of reasons. Participants were randomly assigned to one of two groups in a double-blind manner and supplemented with $100 \mu \mathrm{g}$ Se as L-selenomethionine in a tablet (Health \& Herbs International Ltd, Auckland, New Zealand) or a placebo (Douglas Manufacturing, Auckland, New Zealand) daily for 20 weeks. Blood was collected at baseline and further blood at 5, 10, 15 and 20 weeks after a $10-12 \mathrm{~h}$ overnight fast. Plasma and whole-blood samples were stored at $-80^{\circ} \mathrm{C}$ until analysis of Se, GPx activity and thyroid hormones. Urine samples $\left(24 \mathrm{~h}\right.$ ) were collected at 0,10 and 20 weeks. Total $\mathrm{T}_{3}$, total $\mathrm{T}_{4}$ and TSH were determined in 2004 in samples stored at $-80^{\circ} \mathrm{C}$ at baseline and after 20 weeks of supplementation. Se intakes were determined from two $4 \mathrm{~d}$ weighed diet records, which were completed at weeks 5 and 15. Dietary data were analysed using Diet Cruncher version 1.01 for Windows ${ }^{\mathrm{TM}}$ (Way Down South Software, Dunedin, New Zealand) and the New Zealand Food Composition Food Files version 10.0 for Windows ${ }^{\mathrm{TM}}$ (New Zealand Institute for Crop and Food Research Ltd, Palmerston North, New Zealand).

\section{Study 4: Otago residents (1997-8)}

Two hundred and thirty-three Otago residents aged 18-49 years (114 males and 119 females) were recruited in 1997 and 1998. Complete $24 \mathrm{~h}$ urine collections were made by all subjects for analysis of urinary I and Se. Blood was taken for assays of serum total $\mathrm{T}_{4}, \mathrm{TSH}$ and $\mathrm{Tg}$, and thyroid volumes were measured by ultrasonography. Plasma $\mathrm{Se}$ was determined in samples stored at $-80^{\circ} \mathrm{C}$ in 2004 . The experimental protocol and analytical methods are described elsewhere (Thomson et al. $2001 b)$.

\section{Study 5: Dunedin residents 2001}

One hundred and seventy-two healthy adult Dunedin subjects aged 18-65 years (fifty-eight males and 114 females) were recruited in 2001 for a Se intervention study of 21 weeks. Subjects were randomly assigned to either a placebo treatment consisting of yeast tablets without Se, or $200 \mu \mathrm{g}$ Se daily as Seenriched yeast (Precise; Pharma Nord, Vejle, Denmark), containing selenomethionine as its major single component (54-60\%) (Larsen et al. 2004), and with a Se absorption of $90 \%$ (Larsen et al. 2004; Rayman, 2004). Demographic details including age, household income and smoking status, and habitual intake of Se-rich foods were collected via a questionnaire at baseline. A fasting blood sample was taken at baseline, and at the end of the intervention period for analysis of plasma Se and GPx activity, whole-blood GPx activity, serum TSH, total $\mathrm{T}_{4}$ and total $\mathrm{T}_{3}$. Blood samples were sampled and frozen at $-80^{\circ} \mathrm{C}$ until analysis.

All studies were approved by the Otago Ethics Committee (formerly the Southern Regional Health Authority Ethics Committee of Otago), and all participants gave signed consent before participation. 


\section{Analytical methods}

Selenium. Se concentrations were determined in plasma (studies 2,4 , and 5), whole blood and urine by flow injection hydride generation atomic absorption spectrometry using a sulfuric acid, $\mathrm{H}_{2} \mathrm{O}_{2}$ and vanadium pentoxide reagent mix for sample digestion before analysis (Tiran et al. 1993). Samples were digested in duplicate and each analysed in triplicate using a Perkin-Elmer model 3100 atomic absorption spectrometer (Perkin-Elmer Corp., Norwalk, CT, USA) in combination with an MHS-FIAS200 flow injection hydride generation system and an AS-90 autosampler. Samples of a pooled control sample of the corresponding matrix were analysed during each batch of analyses. Interassay analysis of these controls gave a mean of 1.00 (SD 0.06) $\mu \mathrm{mol} / \mathrm{l}$ (CV 6.1\%) for twenty-eight assays of whole blood and 0.69 (SD $0.05) \mu \mathrm{mol} / \mathrm{l}(\mathrm{CV} 7.9 \%$ ) for nineteen assays of plasma. Analysis of Seronorm Reference Plasma (Nycomed Pharma Diagnostics, Oslo, Norway) with a certified Se value of $0.987 \mu \mathrm{mol} / \mathrm{l}$ gave a value of 0.988 (SD 0.048$) \mu \mathrm{mol} / \mathrm{l}(\mathrm{CV} 4.8 \% ; n$ 5).

In studies 1 and 3, plasma Se concentrations were determined by graphite furnace atomic absorption spectrometry with Zeeman background correction, using a modification of the method of Jacobson \& Lockitch (1988). As earlier, a control pooled sample and an external quality control were analysed with each batch of analyses. Analysis of Utak Reference Plasma (batch no. 66816, product no. 3195; Utak Laboratories Inc., Santa Clarita, CA, USA) with a certified mean value of $1.50 \mu \mathrm{mol} / \mathrm{l}$ gave a mean of 1.50 (SD 0.07$) \mu \mathrm{mol} / \mathrm{l}(\mathrm{CV}$ $4.4 \% ; n 14)$.

Glutathione peroxidase assay. GPx activity was determined in plasma and whole blood using a modification of the method of Paglia \& Valentine (1967) using tertiary butyl hydroperoxide (Thomson et al. 1982) and automated on a Cobas Fara Autoanalyser (Hoffman-La Roche, Basle, Switzerland). Standardised pooled plasma and whole-blood control samples gave mean activities of 19.6 (SD 1.3) units/g Hb with a CV of $6.9 \%$ for forty assays for whole blood and 3.25 (SD 0.20) units/g protein with a CV of $5.4 \%$ for twenty assays of plasma.

Thyroid hormones. Thyroid hormones were measured by RIA.

In study 1 , free $T_{3}$, free $T_{4}$ and TSH were measured using a stratus II analyser (Dade International Inc., Miami, FL, USA) in the Endocrine laboratory, Health Waikato.

In studies 2, 3, 4 and 5, TSH was measured by IRMA-Count ${ }^{\circledR}$ (Diagnostic Products Corporation, Los Angeles, CA, USA), total
$\mathrm{T}_{4}$ by Coat-a-Count (Diagnostic Products Corporation), total $\mathrm{T}_{3}$ by Coat-a-Count, and Tg by double antibody RIA (Coat-a-Count).

Dietary selenium and iodine. Se in duplicate composite diets from study 2 was analysed using the digestion procedure described by Pettersson et al. (1988) coupled with a modification of the semi-automated diamino-napthalene fluorimetric method of Watkinson (1979). Inter-assay analysis of pooled samples gave mean values of 0.68 (SD 0.07) $\mu \mathrm{mol} / \mathrm{kg}(\mathrm{CV} 9.9 \%$ ) for nine assays of a composite diet. Analysis of non-fat milk powder (batch no. 1549; US National Institute of Standards and Technology, Gaithersburg, MD, USA), with a certified mean of $1.39 \mu \mathrm{mol} \mathrm{Se} / \mathrm{kg}$ gave a mean value of 1.40 (SD 0.07) $\mu \mathrm{mol} / \mathrm{kg}$ (CV 9.2\%; $n$ 9). I in the diets was analysed by the method of Moxon \& Dixon (1980) by Roger Hill Laboratories, Hamilton, New Zealand.

\section{Statistical analysis}

Data processing and statistical analysis was carried out using Microsoft Excel (Microsoft Office version 10.1.0; Microsoft Inc., Redwood, WA, USA) and SPSS (version 11 for Macintosh; SSPS Inc., Chicago, IL, USA) or STATA version 8.2 for windows (StataCorp LP, College Station, TX, USA). Interrelationships among measures of Se and thyroid status were determined using linear regression. In addition, in study 4 the data were divided according to plasma Se into two groups; $<0.95 \mu \mathrm{mol} / \mathrm{l}$, which is approximately the level at which the selenoprotein GPx activity is saturated, and $>0.95 \mu \mathrm{mol} / \mathrm{l}$ for comparison of total $\mathrm{T}_{4}$ and thyroid volume. The effects of Se supplementation on thyroid hormones were determined by ANOVA for repeated measures, using the placebo and supplemented groups as covariates, and also using the xtreg package in STATA 8.2 for windows (StataCorp LP). The xtreg command was used to fit a linear mixed effects model to account for the possibility that two measurements on the same individual are more likely to be similar than two measurements on different individuals. A $95 \%$ confidence level and a minimum significance level of $P<0.05$ was required for all analyses. All skewed data were normalised using a logarithmic conversion to the power of ten.

\section{Results}

\section{Selenium and iodine status}

Table 1 summarises results of Se and I excretion and blood measures of $\mathrm{Se}$ status for all studies at baseline. Plasma and

Table 1. Baseline measures of selenium and iodine status for New Zealand subjects in five studies

(Mean values and standard deviations)

\begin{tabular}{|c|c|c|c|c|c|c|c|c|c|c|c|c|c|c|c|}
\hline \multirow[b]{2}{*}{ Study } & \multirow[b]{2}{*}{ Subjects and location } & \multirow[b]{2}{*}{ Year } & \multirow[b]{2}{*}{$n$} & \multicolumn{2}{|c|}{$\begin{array}{l}\text { Plasma Se } \\
(\mu \mathrm{mol} / \mathrm{l})\end{array}$} & \multicolumn{2}{|c|}{$\begin{array}{l}\text { Whole-blood } \\
\text { Se }(\mu \mathrm{mol} / \mathrm{l})\end{array}$} & \multicolumn{3}{|c|}{$\begin{array}{c}\text { Urinary I } \\
\text { concentration }(\mu \mathrm{mol} / \mathrm{l})\end{array}$} & \multicolumn{3}{|c|}{$24 \mathrm{~h}$ urinary I $(\mu \mathrm{mol} / \mathrm{d})$} & \multicolumn{2}{|c|}{$\begin{array}{l}24 \mathrm{~h} \text { urinary } \\
\text { Se }(\mu \mathrm{mol} / \mathrm{d})\end{array}$} \\
\hline & & & & Mean & SD & Mean & SD & Median & Mean & SD & Median & Mean & SD & Mean & $\mathrm{SD}$ \\
\hline 1 & Blood donors, Dunedin & $1993-4$ & 189 & $0.90^{*}$ & 0.14 & $1 \cdot 14$ & 0.18 & 0.33 & $0.37^{*}$ & 0.23 & 0.47 & $0.54^{\star}$ & 0.35 & $0.22^{*}$ & $0 \cdot 10$ \\
\hline 1 & Blood donors, Waikato & $1993-4$ & 144 & 1.08 & 0.18 & 1.34 & 0.18 & 0.42 & 0.49 & 0.31 & 0.60 & 0.70 & 0.43 & 0.33 & 0.15 \\
\hline 2 & Healthy adults, Dunedin & 1995 & 52 & 0.84 & 0.15 & 0.97 & 0.18 & 0.39 & 0.43 & 0.21 & 0.48 & 0.60 & 0.46 & 0.20 & 0.08 \\
\hline 3 & Smokers, Dunedin & $1995-6$ & 60 & 0.97 & 0.16 & $1 \cdot 13$ & 0.18 & 0.28 & 0.36 & 0.29 & 0.52 & 0.55 & 0.32 & 0.19 & 0.12 \\
\hline 4 & Blood donors, Otago & $1997-8$ & 233 & 0.95 & 0.16 & & & 0.43 & 0.46 & 0.26 & 0.59 & 0.68 & 0.39 & & \\
\hline 5 & Healthy adults, Dunedin & 2001 & 172 & $1 \cdot 11$ & 0.19 & & & & & & & & & & \\
\hline
\end{tabular}

* Mean values were significantly different from those for the Waikato group $(P<0.001$; ANOVA). 
whole-blood Se concentrations and urinary I excretion measures were significantly greater in residents of the North Island area of Waikato than in residents of Otago in the South Island of New Zealand $(P<0 \cdot 001)$. Mean Se intakes determined in duplicate composite diets of subjects in study 2 were 35 (SD 7) and 26 (SD 14) $\mu \mathrm{g} / \mathrm{d}$ for males and females, respectively (range 12 $70 \mu \mathrm{g} / \mathrm{d}$ ). In study 3 , intakes of smokers determined from two $4 \mathrm{~d}$ diet records were $53(\mathrm{SD} 18)$ and 38 (SD 16) $\mu \mathrm{g} / \mathrm{d}$, respectively. Mean I intakes in duplicate diets for study 2 were 100 (SD 72) $\mu \mathrm{g} / \mathrm{d}$ for males and 77 (SD 51) $\mu \mathrm{g} / \mathrm{d}$ for females.

\section{Interrelationships among urinary and plasma measures of selenium and iodine status}

Correlations among measures of selenium status. Correlations among measures of Se status were as expected, with high correlation coefficients for the relationship between plasma and whole-blood Se $(0 \cdot 66-0.81 ; P<0.001$ in studies 1,2 and 3$)$ and between whole-blood $\mathrm{Se}$ and GPx activity (0.47-0.65; $P<0.001)$; moderate but significant correlations between plasma Se and GPx activity $(0.33-0.46 ; P<0.01)$, between $24 \mathrm{~h}$ urinary Se excretion and whole-blood Se $(0.30-0.50 ; P<0.05)$ and between $24 \mathrm{~h}$ urinary $\mathrm{Se}$ and plasma Se $(0.39-0.43 ; P<0.05)$. Plasma Se, whole-blood Se and whole-blood GPx activity were related to Se intake after controlling for sex in study 2 ( $r$ 0.33, $P=0.041 ; r 0.35, P=0.037 ; r 0.45, P=0.005$, respectively), and plasma Se with Se intake in study $3(r 0 \cdot 27 ; P=0 \cdot 041)$.

Correlations among measures of iodine status. In study 2, I intake was significantly correlated with $24 \mathrm{~h}$ urinary I excretion ( $r 0.61 ; P<0.001)$ and with urinary I concentration $(r$ 0.33; $P=0.038)$, and inversely correlated with plasma $\operatorname{Tg}(r-0.42$; $P=0.006$ ) but not with plasma $\mathrm{T}_{4}$ nor TSH. Plasma Tg, but not $\mathrm{T}_{4}$ or $\mathrm{TSH}$, was also inversely related to $24 \mathrm{~h}$ I excretion in study $2(r-0.31 ; P=0.049)$ and study $4(r-0.21 ; P=0.003)$.

Correlation coefficients for relationships among urinary I excretion and thyroid hormones and thyroid volume in study 4 have been reported previously (Thomson et al. 2001b). After controlling for sex and age, thyroid volume was correlated with $24 \mathrm{~h} \mathrm{I}$ excretion $(r-0.17 ; P=0.029)$ and the I:creatinine ratio $(r-0.18$; $P=0.018)$, and plasma $\mathrm{Tg}$ with $24 \mathrm{~h} \mathrm{I}$ excretion $(r-0.20$; $P=0.005)$, I:creatinine ratio $(r-0 \cdot 17 ; P=0 \cdot 019)$ and urinary I concentration $(r-0.21 ; P=0.003)$.

Correlations among urinary measures of selenium and iodine status. In study 1 , there was a significant correlation between $24 \mathrm{~h} \mathrm{Se}$ and $24 \mathrm{~h} \mathrm{I}$ excretion $(r 0.31 ; P<0.001)$, which was not altered when controlled for sex or urine volume $(r$ 0.32; $P<0.001)$. Urinary concentrations of Se and I were also significantly correlated $(r 0.48 ; P<0.001)$. This relationship was influenced by urine volume $(r 0.33 ; P<0.001)$ but not by sex.

In study 2 , there was no significant correlation between $24 \mathrm{~h}$ urinary I and $24 \mathrm{~h}$ urinary Se in this group. Urinary concentrations of I and Se were significantly correlated $(r 0.44 ; P=0.003)$, but not after correction for urine volume $(r 0.28 ; P=0 \cdot 07)$.

In study 3 , as for study 1 , there were significant correlations between $24 \mathrm{~h}$ Se and $24 \mathrm{~h}$ I excretions $(r 0.31 ; P=0.017)$ regardless of sex and volume, while urinary concentration of Se and iodide were correlated $(r 0.53 ; P<0.001)$ regardless of sex.

These results confirm that urinary I and Se concentrations, but not total $24 \mathrm{~h}$ excretions, are influenced by urine volume.

Interactions among measures of selenium status and thyroid status. There were no significant correlations between measures 
of Se status (plasma and whole-blood Se, plasma and whole-blood GPx activities) and measures of thyroid status (plasma TSH, $\mathrm{T}_{4}$, $\mathrm{T}_{3}$ ) after controlling for sex, either at baseline for studies 1,2 , 3,4 or 5 or after supplementation in studies 2, 3 or 5. However, in study 2 there was a non-significant negative correlation between whole-blood $\mathrm{Se}$ and $\mathrm{T}_{4}$ after supplementation $(r-0 \cdot 25$; $P=0.088$ ).

When subjects in study 4 were divided into two groups according to plasma Se $(<0.95 \mu \mathrm{mol} / \mathrm{l} ;>0.95 \mu \mathrm{mol} / \mathrm{l})$ plasma $\mathrm{T}_{4}$ was lower in male but not female subjects with plasma Se above that required for maximal activities of GPx and selenoprotein $P$ (Duffield et al. 1999) than in those with lower plasma Se $(P=0.009)$.

\section{Effect of selenium supplementation on thyroid hormones}

Se supplementation resulted in significant increases in plasma Se concentrations $(P<0.001)$ in comparison with placebo groups in all three supplementation studies (studies 2, 3 and 5), but only small changes in plasma $T_{4}$ and the $T_{3}: T_{4}$ ratio were observed (Table 2). In study 2, Se supplementation reduced $\mathrm{T}_{4}$ levels when results for all supplemented subjects were combined and compared with baseline levels and the placebo group $(P=0.0045)$. However, in studies 3 and 5 there were only small decreases in plasma $\mathrm{T}_{4}$ and in study 3 , a small increase in the $\mathrm{T}_{3}: \mathrm{T}_{4}$ ratio, which were not significantly different from placebo groups.

\section{Discussion}

We have used data from five different studies, two observational and three interventional, to explore possible interrelationships among Se, I and thyroid status in the New Zealand population. Blood Se concentrations of residents in Waikato in the North Island were greater than those of Otago residents in the South Island, due mainly to the greater use of Australian wheat with higher Se concentrations in the North Island (Thomson \& Robinson, 1996; Thomson, 2004b). Expected positive relationships between Se intake and markers of Se status were observed at baseline, and correlations were strengthened after supplementation due to the wider range of Se status. Significant positive relationships between blood Se and GPx activities and selenoprotein $\mathrm{P}$ concentrations indicate that the Se status in New Zealand is not sufficient for maximal activity of these selenoproteins. Similarly, expected relationships between I intake and status were observed, with high correlations between I intake and I excretion and with plasma Tg, which reflected the marginal I status.

Although correlations between measures of $\mathrm{Se}$ and thyroid status were not significant, mean plasma $\mathrm{T}_{4}$ was lower in males with higher plasma Se in study 4. In addition, there was: (a) a reduction in $\mathrm{T}_{4}$ levels after Se supplementation in study 2 and non-significant reductions in studies 3 and 5; (b) a negative relationship between whole-blood $\mathrm{Se}$ and $\mathrm{T}_{4}$ after supplementation. The present results indicate a small effect of Se status on $\mathrm{T}_{4}$ levels, which is consistent with Se's role in the deiodinases, suggesting an inhibition in the conversion of $\mathrm{T}_{4}$ to $\mathrm{T}_{3}$. Further specific studies of the effect of Se status and Se supplementation on thyroid hormones and thyroid volume is warranted, in particular the effect on the $\mathrm{T}_{3}: \mathrm{T}_{4}$ ratio, which, as suggested by Zimmermann \& Kohrle (2002), might be a valid indicator of decreased $\mathrm{T}_{4}$ conversion to the active hormone $\mathrm{T}_{3}$ under conditions of $\mathrm{Se}$ deficiency.

Several other studies have indicated changes in thyroid hormone levels, depending on the extent of Se and I deficiency. Kvícala et al. (1995) reported significant relationships over a range of measures of Se status and thyroid hormone parameters $\left(\mathrm{T}_{4}\right.$ and $\mathrm{T}_{3}: \mathrm{T}_{4}$ ) in 380 Czech inhabitants aged 6-65 years, but not always in all of the narrower age ranges. Olivieri et al. (1996) reported a highly significant positive correlation between the $\mathrm{T}_{3}: \mathrm{T}_{4}$ ratio and indices of Se status in healthy elderly Italian subjects with marginal Se status, concluding that reduced peripheral conversion of $\mathrm{T}_{4}$ is related to inadequate Se status in the elderly. Se supplementation resulted in a reduction of $\mathrm{T}_{4}$ but no changes in the $\mathrm{T}_{3}: \mathrm{T}_{4}$ ratio (Olivieri et al. 1995). In the 'older elderly' Italians, higher TSH and lower free $\mathrm{T}_{3}: \mathrm{T}_{4}$ ratios were associated with lower blood Se levels than in the 'adult elderly' (Ravaglia et al. 2000). Se supplementation attenuated the decrease in the $\mathrm{T}_{3}: \mathrm{T}_{4}$ ratio in these subjects.

An effect of low Se status or Se supplementation on thyroid hormone metabolism has also been observed in children with phenylketonuria (Terwolbeck et al. 1993; Calomme et al. 1995), in chronic uraemic patients on haemodialysis (Napolitano et al. 1996), in congenital hypothyroidism (Chanoine et al. 2001), and as a result of altered Se status after trauma (Berger et al. 1996, 2001). On the other hand, others have not shown evidence of any effect of marginal Se deficiency on thyroid hormones or thyroid volume (Erdogan et al. 2001; Cinaz et al. 2004). Zagrodski et al. (2000) have suggested that, in subjects with both Se and I deficiency, lack of observable differences in TSH and free $\mathrm{T}_{4}$ could be due to the overlapping effects of two processes: (1) decreased $\mathrm{T}_{4}$ secretion caused by I deficiency reflected by lower plasma free $T_{4}$ concentrations; (2) an increase in free $T_{4}$ associated with reduced iodothyronine deiodinase activity caused by Se deficiency. On the other hand, there may be other factors that influence thyroid hormone levels, including adaptations that occur in the pathways involved in thyroid hormone synthesis that act to maintain normal thyroid status (Arthur et al. 1999).

Lack of significant associations between plasma Se and thyroid status, and only small changes in $\mathrm{T}_{4}$ suggest that the Se status in New Zealand is adequate for optimal activity of the deiodinases. The present results and those of other studies are consistent with a hierarchy of importance of selenoproteins. Deiodinases rank high in the hierarchy of Se supply, and are therefore less likely to be affected by marginal Se deficiency than GPx, which is lower on the hierarchy. Mean baseline Se levels in the five studies reflect the gradual increase in Se status in New Zealand residents over that period of time (Thomson \& Robinson, 1996; Thomson, 2004b). Apart from study 2, in which subjects were screened for low Se status, the baseline plasma Se in healthy adults from Otago rose from $0.90 \mu \mathrm{mol} / \mathrm{l}$ in 1993 to $1.11 \mu \mathrm{mol} / \mathrm{l}$ in 2001 . Baseline Se levels in the later supplementation studies (study 3, $0.97 \mu \mathrm{mol} / \mathrm{l} \quad(77 \mu \mathrm{g} / \mathrm{l}) ; \quad$ study $5,1.11 \mu \mathrm{mol} / \mathrm{l} \quad(88 \mu \mathrm{g} / \mathrm{l}))$ were higher than that in the earlier study $2(0.84 \mu \mathrm{mol} / \mathrm{l}(66 \mu \mathrm{g} / \mathrm{l}))$ in which an effect of Se supplementation on $\mathrm{T}_{4}$ was observed. The present results therefore suggest that plasma Se of about 0.82$0.90 \mu \mathrm{mol} / \mathrm{l}(65-70 \mu \mathrm{g} / \mathrm{l})$ may be adequate for optimal function of the deiodinases. Daily dietary Se intake associated with this plasma concentration is about $30-35 \mu \mathrm{g} / \mathrm{d}$ (Thomson, 2004a). This compares with a plasma Se concentration of 1.00$1 \cdot 14 \mu \mathrm{mol} / \mathrm{l}(85-90 \mu \mathrm{g} / \mathrm{l})$ and dietary Se intake of $45-55 \mu \mathrm{g} / \mathrm{d}$ for maximal GPx activities (Thomson, 2004a). 
The modest reduction in $\mathrm{T}_{4}$ and increase in the $\mathrm{T}_{3}: \mathrm{T}_{4}$ ratio with higher Se status, however, warrant further investigation, especially in groups particularly vulnerable to inadequate Se and I intakes, such as the elderly, pregnant women and young children. Normal thyroid status during pregnancy and early childhood is essential for optimal mental and physical development of the fetus and infant. If the I status is allowed to decline further in New Zealand (Thomson, 2004b), the maintenance of an adequate Se status is likely to become of even greater importance.

\section{Acknowledgements}

We wish to thank the participants for their willing cooperation, Jody Joseph, Andrew Colls and Stephen Woodruffe for technical assistance, Margaret Waldron for venepuncture and Mark Wohlers for assistance with statistical analysis. The Health Research Council of New Zealand, The National Heart Foundation of New Zealand, The Otago Medical Research Foundation and the Ministry of Health of New Zealand funded these studies.

\section{References}

Arthur JR \& Beckett GJ (1999) Thyroid function. Br Med Bull 55, $658-668$.

Arthur JR, Beckett GJ \& Mitchell JH (1999) The interactions between selenium and iodine deficiencies in man and animals. Nutr Res Rev 12, $55-73$.

Berger MM, Lemarchand-Béraud T, Cavadini C \& Chioléro R (1996) Relations between the selenium status and the low $\mathrm{T}_{3}$ syndrome after major trauma. Intensive Care Med 22, 575-581.

Berger MM, Reymond MJ, Shenkin A, Rey F, Wardle C, Cayeux C, Schindler C \& Chiolero RL (2001) Influence of selenium supplements on the post-traumatic alterations of the thyroid axis: a placebo-controlled trial. Intensive Care Med 27, 91-100.

Calomme MR, Vanderpas JB, Francois B, van Caillie-Bertrand M, Herchuelz A, Vanovervelt N, van Hoorebeke C \& Vanden Berghe DA (1995) Thyroid function parameters during a selenium repletion/ depletion study in phenylketonuric subjects. Experentia 51, $1208-1215$

Chanoine J-P, Neve J, Wu S, Vanderpas J \& Bourdoux P (2001) Selenium decreases thyroglobulin concentrations but does not affect the increased thyroxine-to-triiodothyronine ratio in children with congenital hypothyroidism. J Clin Endocrinol Metab 86, 1160-1163.

Cinaz P, Karakas DS, Camurdan MO, Bideci A, Ayvali ED \& Yucel C (2004) Goiter prevalence, serum selenium, and urine iodine status in a previously iodine-deficient area in Turkey. Biol Trace Elem Res 100, 185-193.

Combs GF Jr (2001) Selenium in global food systems. Br J Nutr 85, 517-547.

Diplock A (1993) Indexes of selenium status in human populations. Am J Clin Nutr 57, 256S-258S.

Duffield AJ \& Thomson CD (1999) A comparison of methods of assessment of dietary selenium intakes in Otago, New Zealand. Br J Nutr 82, $131-138$

Duffield AJ, Thomson CD, Hill KE \& Williams S (1999) An estimation of selenium requirements for New Zealanders. Am J Clin Nutr 70, 896-903.

Erdogan M, Erdogan G, Sav H, Gullu S \& Kamel N (2001) Endemic goiter, thiocyanate overload, and selenium status in school-age children. Biol Trace Elem Res 79, 121-130.

Jacobson BH \& Lockitch G (1988) Direct determination of selenium in serum by graphite-furnace atomic absorption spectrometry with deuterium background detection and a reduced palladium modifier: age-specific reference ranges. Clin Chem 34, 709-714.
Kvícala J, Zamrazil V, Soutorová M \& Tomíska F (1995) Correlations between parameters of body selenium status and peripheral thyroid parameters in the low selenium region. Analyst 120, 959-965.

Larsen EH, Hansen M, Paulin H, Moesgaard S, Reid M \& Rayman M (2004) Speciation and bioavailability of selenium in yeast-based intervention agents used in cancer chemoprevention studies. J AOAC Int $\mathbf{8 7}$, $225-232$.

Moxon RED \& Dixon EJ (1980) Semi-automatic method for the determination of total iodine in foods. Analyst 105, 344-352.

Napolitano G, Bonomini M, Bomba G, Bucci I, Todisco V, Albertazzi A \& Monaco F (1996) Thyroid function and plasma selenium in chronic uremic patients on hemodialysis treatment. Biol Trace Elem Res 55, $221-230$

Olivieri O, Girelli D, Azzini M, Stanzila AM, Russo C, Ferroni M \& Corrocher R (1995) Low selenium status in the elderly influences thyroid hormones. Clin Sci 89, 637-642.

Olivieri O, Girelli D \& Stanzial AM (1996) Selenium, zinc, and thyroid hormones in healthy subjects. Biol Trace Elem Res 51, 31-41.

Paglia DC \& Valentine WN (1967) Studies on quantitative and qualitative characterization of erythrocyte glutathione peroxidase. J Lab Clin Med 70, $158-169$.

Paterson E (2000) Selenium, oxidant stress and smoking. PhD Thesis, University of Otago.

Pettersson J, Hansson L, Ornemark U \& Olin A (1988) Fluorimetry of selenium in body fluids after digestion with nitric acid, magnesium nitrate hexahydrate, and hydrochloric acid. Clin Chem 34, 1908-1910.

Ravaglia G, Forti P, Maioli F, Nesi B, Pratelli L, Savarino L, Cucinotta D \& Cavalli G (2000) Blood micronutrient and thyroid hormone concentrations in the oldest-old. J Clin Endocrinol Metab 85, 2260-2265.

Rayman MP (2004) The use of high-selenium yeast to raise selenium status: how does it measure up? Br J Nutr 92, 557-573.

Robinson MF (1989) Selenium in human nutrition in New Zealand. Nutr Rev 47, 99-107.

Skeaff S, Ferguson E, Valeix P, Gibson R \& Thomson CD (2005) Are breast-fed infants and toddlers in New Zealand at risk of iodine deficiency? Nutrition 21, 325-331.

Skeaff SA, Thomson CD \& Gibson RS (2002) Mild iodine deficiency in a sample of New Zealand schoolchildren. Eur J Clin Nutr 56, 1169-1175.

Terwolbeck K, Behne D, Meinhold H, Menzel H \& Lombeck I (1993) Increased plasma T4-levels in children with low selenium state due to reduced type I iodothyronine $5^{\prime}$ deiodinase activity? J Trace Elem Electrolytes Health Dis 7, 53-55.

Thomson CD (2004a) Assessment of requirements for selenium and adequacy of selenium status: a review. Eur J Clin Nutr 58, 391-402.

Thomson CD (2004b) Selenium and iodine intakes and status in New Zealand and Australia. Br J Nutr 91, 661-672.

Thomson CD, Colls AJ, Conaglen JV, Macormack M, Stiles M \& Mann J (1997a) Iodine status of New Zealand residents as assessed by urinary iodide excretion and thyroid hormones. Br J Nutr 78, 901-912.

Thomson CD, Colls AJ, Styles M \& Conaglen J (1997b) Urinary iodide excretion in New Zealand residents. In Trace Elements in Man and Animals TEMA-9, pp. 118-119 [PWF Fischer, MR L'Abbé, KA Cockell and RS Gibson, editors]. Ottawa: NRC Research Press.

Thomson CD, Packer MA, Butler JA, Duffield AJ, O'Donaghue KL \& Whanger PD (2001a) Urinary selenium and iodine during pregnancy and lactation. J Trace Elem Med Biol 14, 210-217.

Thomson CD \& Robinson MF (1996) The changing selenium status of New Zealand residents. Eur J Clin Nutr 50, 107-114.

Thomson CD, Robinson MF, Butler JA \& Whanger PD (1993) Long-term supplementation with selenate and selenomethionine: selenium and glutathione peroxidase (EC 1.11.1.19) in blood components of New Zealand women. Br J Nutr 69, 577-588.

Thomson CD, Robinson MF, Campbell DR \& Rea HM (1982) Effect of prolonged supplementation with daily supplements of selenomethionine and sodium selenite on glutathione peroxidase activity in blood of New Zealand residents. Am J Clin Nutr 36, 24-31. 
Thomson CD, Woodruffe S, Colls AJ, Joseph J \& Doyle TC (2001b) Urinary iodine and thyroid status of New Zealand residents. Eur J Clin Nutr 55, 387-392.

Tiran B, Tiran A, Rossipal E \& Lorenz O (1993) Simple decomposition procedure for determination of selenium in whole blood, serum and urine by hydride generation atomic absorption spectroscopy. J Trace Elem Electrolytes Health Dis 7, 211-216.

Watkinson JH (1979) Semi-automated flurometric determination of nanogram quantities of selenium in biological material. Analyt Chim Acta 105, 319-325.
World Health Organization, United Nations International Children's Emergency Fund \& International Council for the Control of Iodine Deficiency Disorders (1994) Indicators for Assessing Iodine Deficiency Disorders and Their Control Through Salt Iodization. Geneva: WHO. Zagrodzki P, Szmigiel H, Ratajczak R, Szybinski Z \& Zachwieja Z (2000) The role of selenium in iodine metabolism in children with goiter. Environ Health Perspect 108, 67-71.

Zimmerman M \& Kohrle J (2002) The impact of iron and selenium deficiencies on iodine and thyroid metabolism: biochemistry and relevance to public health. Thyroid 12, 867-878. 